\title{
Clinical Presentation and Laboratory Features in Pediatric Typhoid Fever Patient Susceptibility to First-line Antibiotic Therapy
}

\author{
Dewi Ratnasari, ${ }^{1}$ Djatnika Setiabudi, ${ }^{2}$ Lulu Eva Rakhmilla ${ }^{3}$ \\ ${ }^{1}$ Faculty of Medicine Universitas Padjadjaran, ${ }^{2}$ Department of Child Health Faculty of Medicine, \\ Universitas Padjadjaran/Dr. Hasan Sadikin General Hospital Bandung, ${ }^{3}$ Department of \\ Epidemiology and Biostatistics Faculty of Medicine Universitas Padjadjaran
}

\begin{abstract}
Background: RTyphoid fever remainsa serious health problem in the world. The main cause of this disease is Salmonella enterica serovar Typhi. These microbes have developed resistance to first-line antibiotics (chloramphenicol, ampicillin, and co-trimoksazol) since 1950. Clinical presentation and laboratory features conducted in children infected with resistant strains tend to be more severe. The objective of this study was to determine the differences of clinical presentation and laboratory features in pediatric typhoid fever patient susceptibility to first-line antibiotics.

Methods: This was an analytical cross-sectional study of total 119 typhoid fever children with positive blood culture of Salmonella Typhi based on medical data in Department of Child Health Dr. Hasan Sadikin General Hospital, Bandung during 2008-2012. Inclusion criteria included 76 patients with age range 1-15 years old, given an antibiotic, and had susceptibility test done. Numerical variable was the duration of fever in patients after given an antibiotic. Categorical variable included hepatomegaly, diarrhea, platelet count at admission, and leukocyte count at admission. Data were analyzed using a Mann-Whitney and Chi-square test.

Results: There was no statistically significant difference in the duration of fever, leucocyte count at admission, and thrombocyte count at admission between sensitive and resistant response to chloramphenicol, ampicillin, and co-trimoksazol ( $p>0.05$ ). Leucocyte count at admission in children with sensitive and resistant strain to ampicillin almost showed a difference $(\mathrm{p}=0.07)$ but still not statistically significant difference.

Conclusions: There is no difference of clinical presentation and laboratory features in pediatric typhoid fever patient susceptible to first-line antibiotics. [AMJ.2015;2(4):584-90]
\end{abstract}

Keywords: Clinical presentation, First line antibiotics, laboratory features, Salmonella Typhi

\section{Introduction}

Typhoid fever is an infection caused by Salmonella enterica serovar Typhi (S. Typhi), a gram-negative bacteria. It remains as a serious health problem due to high mortality rate in the world. ${ }^{1,2}$ Based on World Health Organization (WHO) study in 2000, typhoid fever is accounted for over 2.16 million cases worldwide with at least 216.000 annual death. In Indonesia, based on Basic Health Research Institution (Riset Kesehatan Dasar/ RISKESDAS) study, held by the Indonesian Ministry of Health, there are 1,6\% mortality cases caused by typhoid fever from 4552 total mortality cases in all ages in $2007 .^{3}$

Based on a study conducted in Kathmandu Medical College teaching hospital from
July 2004-June 2005, clinical presentation in children with typhoid fever were fever (100\%), headache (82.6\%), vomiting (21.7\%), diarrhea $(28.3 \%)$, hepatomegaly (18.1\%), and splenomegaly (28.3\%).,5 Besides, laboratory test shows leukopenia (3\%) and thrombocytopenia (4.8\%) according to a study from May 2002-April 2004 in Batra Hospital and Medical Research Center, New Delhi, India. ${ }^{6}$

The first treatment used in 1948 for typhoid fever was chloramphenicol. Chloramphenicolresistant Salmonella Typhi cases is first reported in England (1950) and followed by India (1972). ${ }^{4,7}$ In resistant cases to firstline antibiotics, severe presentation could be present in children with typhoid fever. ${ }^{4,8}$ In Aga Khan University, Karachi, Pakistan, during

Correspondence: Dewi Ratnasari, Faculty of Medicine, Universitas Padjadjaran, Jalan Raya Bandung-Sumedang Km.21, Jatinangor, Sumedang, Indonesia, Phone: +62 8782779846 Email: deardewir@live.com 
Dewi Ratnasari, Djatnika Setiabudi, Lulu Eva Rakhmilla: Clinical Presentation and Laboratory Features in 585 Pediatric Typhoid Fever Patient Susceptibility to First-line Antibiotic Therapy

2010 a resistant case in children with typhoid fever had severe presentation including fever $(100 \%)$, hepatomegaly (88\%), splenomegaly (46\%), diarrhea (74\%), encephalopathy (8\%), and pneumonia $(3.2 \%) .{ }^{9}$

Laboratory features such as leukopenia (18.66\%) and thrombocytopenia (2.66\%) were shown in Government Medical College in Pediatric Ward, Ahmedabad, Gujarat. ${ }^{11} 10$

There are many resistant cases of first-line antibiotics around the world. Chloramphenicol, ampicillin, and co-trimoksazol resistant cases are serious problems that need to be concerned beacuse it could elevate the mortality rate. This study aimed to determine the differences of clinical presentation and laboratory test based on susceptibility of Salmonella Typhi to firstline antibiotic (chloramphenicol, ampicillin, and co-trimoksazol) at Dr. Hasan Sadikin General Hospital, Bandung, Indonesia. Clinical presentation of this study includes duration of fever after given an antibiotic, diarrhea and hepatomegaly. A laboratory test in this study includes platelet count at admission and leukocyte count at admission.

\section{Methods}

Patients with positive blood culture of Salmonella Typhi had susceptibility test done during January 2008-December 2013 in the Child Health Department of Dr. Hasan Sadikin General Hospital, Bandung, Indonesia were chosen as a subject of the study. Inclusion criteria in this study included 76 patients with age range 1-15 years old, given an antibiotic, and had susceptibility test done. The exclusion criteria included 43 patients with other infection, had not susceptibility test done, and incomplete data.

Analysis of the characteristics, clinical, and hematologic features of patients diagnosed with typhoid, as well as an analysis of sensitivity profiles of Salmonella Typhi isolates were collected. Data were collected from medical record in Clinical Pathology Department and Medical Record Installation with permission from Health Research Ethics Committee of Dr. Hasan Sadikin General Hospital, Bandung, Indonesia. In this study, it is used susceptibility on antibiotics as an independent variable and

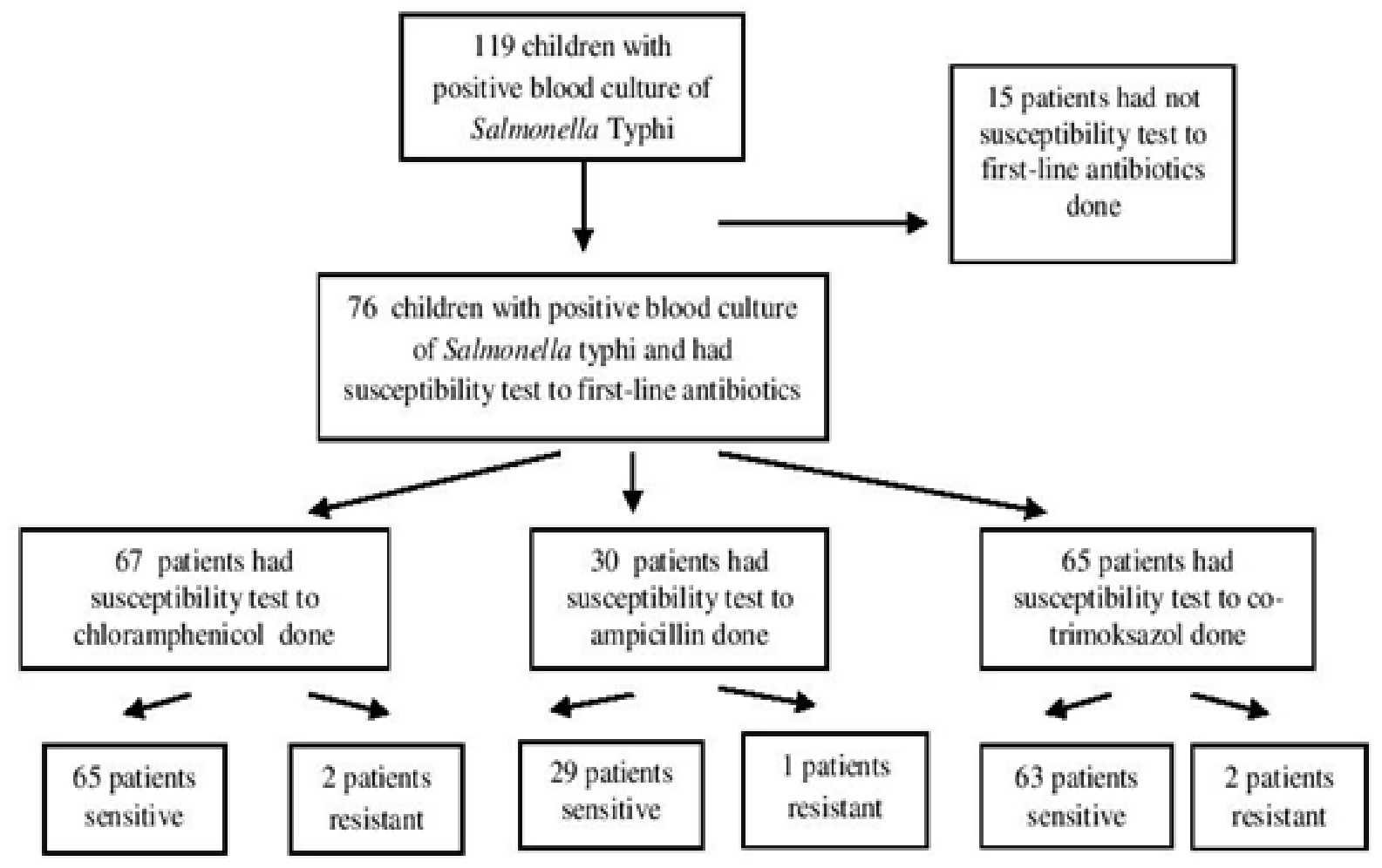

Figure 1 Study Profile 
Table 1 Characteristics of Typhoid Fever in Children Patients with Positive Culture of Salmonella Typhi based on Numerical Variable

\begin{tabular}{lc}
\hline Variable & Median (Min-Max) \\
Age (years) & $\mathbf{8 ~ ( 1 - 1 5 ) ~}$ \\
\hline Duration of hospitalization (days) & $7.50(2-28)$ \\
Duration of fever (days) & $4(0-16)$ \\
Leukocyte count during hospitalization (/mm3) & $5,250(1,700-11,200)$ \\
Leukocyte count at admission (/mm3) & $5,550(1,700-68,000)$ \\
Platelet count during hospitalization (/mm3) & $139,500(1,200-379,000)$ \\
Platelet count at admission (/mm3) & $142,000(3,000-406,000)$ \\
\hline
\end{tabular}

clinical presentation and laboratory features as a dependent variable. Each variable was susceptibility to first-line to antibiotics that shown in culture test result, body temperature $>40$ oC as a fever, excessive and frequent evacuation ( $>3 \mathrm{x} /$ day) of watery feces as a diarrhea, abnormal enlargement of liver as a hepatomegaly, total of white cells count $<5000 /$ $\mathrm{mm} 3$ as a leukopenia, and total thrombocyte count $<150000 / \mathrm{mm} 3$ as a thrombocytopenia.

Based on normality test analysis, the data were not a normal distribution therefore it was used median with minimum and maximum data to describe all the cases based on the variable. Total sampling method was collected from the medical record. The data were analyzed using the Mann-Whitney test and chi-square analysis test for numerical and categorical variable. Numerical variable in this study was the duration of fever in patients after given an antibiotic. Categorical variable in this study included hepatomegaly, diarrhea, platelet count at admission, and leukocyte count at admission. The analysis was performed using statistical software applications.

\section{Results}

In this study, data were collected from 119 children with positive blood culture of Salmonella typhi, of which 43 data were excluded based on exclusion criteria. There were 76 analyzed data based on susceptibility test to first-line antibiotics. (Figure 1)

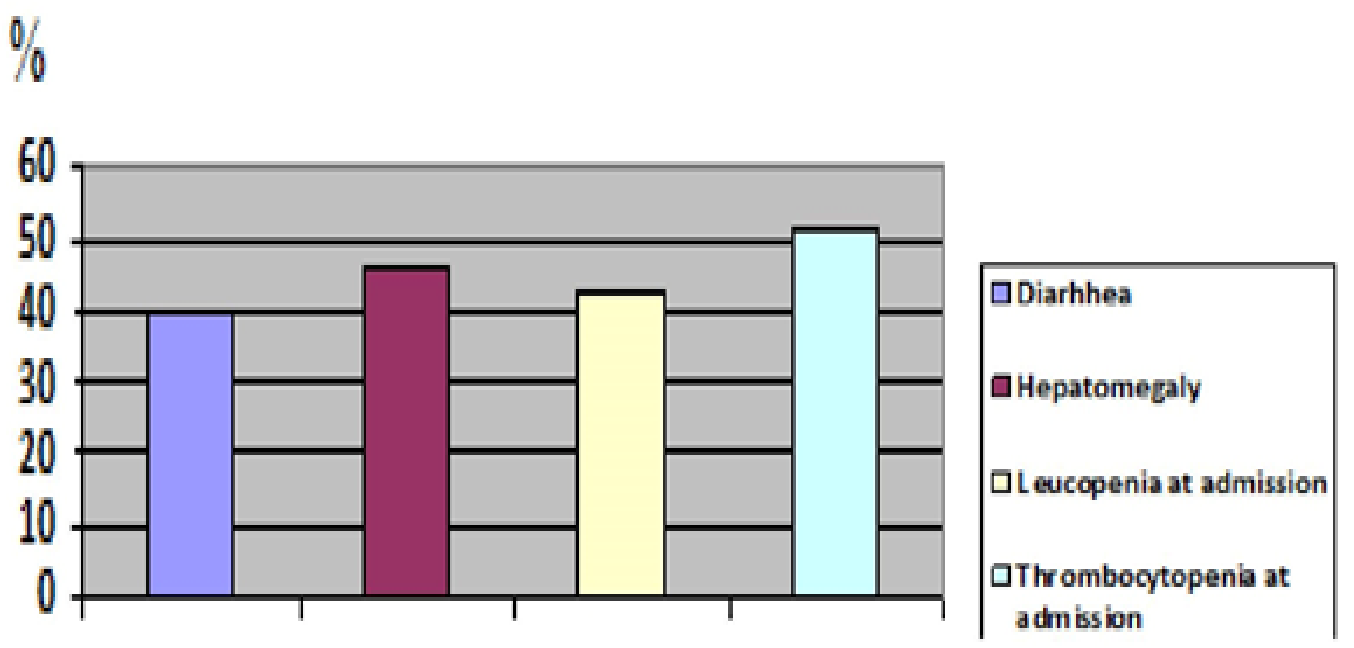

Clinical Sign

Figure 2 Characteristics of Typhoid Fever in Children Patients with Positive Culture of Salmonella Typhi based on Categorical Variable 
Dewi Ratnasari, Djatnika Setiabudi, Lulu Eva Rakhmilla: Clinical Presentation and Laboratory Features in 587 Pediatric Typhoid Fever Patient Susceptibility to First-line Antibiotic Therapy

Table 2 Clinical Presentation and Laboratory Features in Typhoid Fever due to Salmonella Typhi Infection in Children based on Their Susceptibility to First-Line Antibiotics based on Numerical Variable

\begin{tabular}{|c|c|c|c|c|c|c|}
\hline & $\begin{array}{c}\text { Duration } \\
\text { of Fever } \\
\text { (days)* }\end{array}$ & $\mathbf{p}^{* *}$ & $\begin{array}{c}\text { Leucocyte } \\
\text { Count at } \\
\text { Admission } \\
(103 / \mathrm{mm} 3)^{*}\end{array}$ & $\mathbf{p}^{* *}$ & $\begin{array}{c}\text { Platelet } \\
\text { Count at } \\
\text { Admission } \\
(103 / \mathrm{mm} 3)^{*}\end{array}$ & $\mathbf{p}^{* *}$ \\
\hline \multicolumn{7}{|c|}{ Chloramphenicol } \\
\hline Sensitive & 4 & \multirow{2}{*}{0.76} & 5.6 & \multirow{2}{*}{0.26} & 138 & \multirow[t]{2}{*}{0.1} \\
\hline Resistant & 4.5 & & 3.8 & & 81 & \\
\hline \multicolumn{7}{|l|}{ Ampicillin } \\
\hline Sensitive & 3 & \multirow{2}{*}{0.6} & 5.8 & \multirow{2}{*}{0.07} & 150 & \multirow[t]{2}{*}{0.93} \\
\hline Resistant & 2 & & 6.8 & & 143 & \\
\hline \multicolumn{7}{|c|}{ Co-trimoksazol } \\
\hline Sensitive & 4 & \multirow{2}{*}{0.25} & 5.2 & \multirow{2}{*}{0.44} & 138 & \multirow[t]{2}{*}{0.65} \\
\hline Resistant & 2.5 & & 3.6 & & 125.5 & \\
\hline
\end{tabular}

The susceptibility tests were performed using chloramphenicol, ampicillin, and co-trimoxazole with the results grouped as sensitive and resistant (Figure 1). Susceptibility test to chloramphenicol had been done to 67 patients $(88.2 \%)$ included patients had susceptibiliy test to all first-line antibiotics done $(25.4 \%)$, to chloramphenicol and ampicilllin (6\%), and patients had susceptibility test done to chloramphenicol and co-trimoksazol (68.7\%). Besides, susceptibility test to ampicillin had been done to 30 patients $(39.5 \%)$ included patients had susceptibility test done only to ampicillin $(13.3 \%)$, to all first-line antibiotics $(56.7 \%)$, to ampicillin-chloramphenicol (13.3\%), and to ampicillin-co-trimoksazol (16.7\%). Susceptibility test to co-trimoksazol had been done to 65 patients $(85.5 \%)$ included patients had susceptibility to all first-line antibiotic $(26.2 \%)$, to cotrimoksazol-chloramphenicol (66.2\%), and patients had susceptibility to

Table 3 Clinical Presentation and Laboratory Features in Typhoid Fever due to Salmonella Typhi Infection in Children based on Their Susceptibility to First-Line Antibiotics based on Categorical Variable

\begin{tabular}{|c|c|c|c|c|c|c|c|c|}
\hline & $\begin{array}{c}\text { Diarrhea } \\
\text { (\%)* }\end{array}$ & $\mathbf{p}^{* *}$ & $\begin{array}{l}\text { Hepatome- } \\
\text { galy } \\
(\%)^{*}\end{array}$ & $\mathbf{p}^{* *}$ & $\begin{array}{c}\text { Leukope- } \\
\text { nia at } \\
\text { Admission } \\
(\%)^{*}\end{array}$ & $\mathbf{p}^{* *}$ & $\begin{array}{l}\text { Thrombocytope- } \\
\text { nia at Admission } \\
\text { (\%)* }\end{array}$ & $\mathbf{p}^{* *}$ \\
\hline \multicolumn{9}{|c|}{ Chloramphenicol } \\
\hline Sensitive & 36 & \multirow{2}{*}{0.53} & 47 & \multirow{2}{*}{1} & 43 & \multirow[t]{2}{*}{0.19} & 52 & \multirow[t]{2}{*}{0.49} \\
\hline Resistant & 0 & & 50 & & 100 & & 100 & \\
\hline \multicolumn{9}{|l|}{ Ampicillin } \\
\hline Sensitive & 44 & \multirow{2}{*}{0.6} & 34 & \multirow{2}{*}{0.36} & 38 & \multirow[t]{2}{*}{1} & 48 & \multirow[t]{2}{*}{1} \\
\hline Resistant & 0 & & 100 & & 0 & & 100 & \\
\hline \multicolumn{9}{|c|}{ Co-trimoksazol } \\
\hline Sensitive & 41 & \multirow{2}{*}{0.24} & 44 & \multirow{2}{*}{1} & 44 & 1 & 52 & \multirow[t]{2}{*}{0.49} \\
\hline Resistant & 0 & & 50 & & 50 & & 100 & \\
\hline
\end{tabular}


cotrimoksazol-ampicillin (7.7\%).

The average age of all cases was 8 years old. Clinical presentation and laboratory features such as diarrhea (39.5\%), hepatomegaly (46.1\%), leucopenia at admission (42.1\%), and thrombocytopenia at admission (51.3\%) were presented (Table 1 and Figure 2).

Based on the analysis using Mann-Whitney method, there were no statistically significant difference in the duration of fever, leucocyte count at admission, and thrombocyte count at admission between sensitive and resistant response to chloramphenicol, ampicillin, and co-trimoksazol ( $p>0.05)$. Leucocyte count at admission in children with sensitive and resistant strain to ampicillin almost showed a difference $(\mathrm{p}=0.07)$ but still not statistically significant difference (Table 2).

Comparison of clinical presentation and laboratory features (diarrhea, hepatomegaly, leukopenia at admission, thrombocytopenia at admission) in typhoid fever due to Salmonella Typhi infection in children based on their susceptibility to first-line antibiotics (sensitive and resistant) were analyzed using Chi-square method. All the $p$ values were above 0.05 for all clinical presentation. It was shown that there was no statistically significant difference in the clinical presentation and laboratory features of sensitive and resistant Salmonella Typhi isolates to first-line antibiotics (Table 3).

\section{Discussion}

In this study, overall cases of typhoid fever in children due to Salmonella typhi infection during January 2008-December 2012 are 119 cases. But, there is another infection that can alter the results of clinical presentation and a few of data that are incomplete, so the data are excluded from this study. There are only 76 cases included in the study. The average age is 8 years old. It is similar to a study conducted in Government Medical College in 2011 shown that fever was frequently presented on 6-12 years old children hospitalized in Pediatric Ward. ${ }^{11}$

Hepatomegaly is more frequent than diarrhea (42\% vs $23 \%$ ) in typhoid children patients based on study in Ward of Pediatric Infectious Diseases in Turkey in 2001. ${ }^{6}$ Based on this study, there are similar frequency for hepatomegaly (46.1\%) and diarrhea (39.5\%).

A study in Dr. Hasan Sadikin General Hospital, Bandung, conducted by Alam, during 2006-2010 and study in Apollo Hospital, India during 2009-2011 showed that resistant cases to first-line antibiotics (ampicillin, chloramphenicol, and co-trimoksazol) were low. Both study discovered that the first-line antibiotics could remain as a treatment for typhoid fever in children. ${ }^{12,13}$ In this study, first-line antibiotics also could remain as first choice of tratment for typhoid fever in children. In 2012, there were also evidence that first-line antibiotics remain as a choice for typhoid treatment in Carolus Hospital, Jakarta. The sensitivity rate to first-line antibiotics remained high from 247 isolates collected during 2002-2010. ${ }^{14}$

Based on study in Chennai, India, an increased sensitivity was also reported for chloramphenicol (97.5\%), ampicillin (67.5\%), and co-trimaxazole (97.5\%). ${ }^{15}$ Based on study in Karachi, Pakistan on 2011, there was a different result which are resistant cases to first-line antibiotics presented above $50 \%$. In 2011 there were $89.7 \%, 82.8 \%$, and $31.0 \%$ resistant cases to first-line antibiotics to ampicillin, chloramphenicol and cotrimozaxole respectively based on study in General Hospital, Funtua, Katsina state of Nigeria. ${ }^{16,17}$ Many factors could lead to the emergence of resistant strains or resistant cases such as lack of knowledge, physicians change, different antibiotics unnecessarily during the treatment of typhoid fever, and indiscriminate use of drugs. ${ }^{8,18}$

A study conducted in King Edward Memorial Hospital, Mumbai, from the data isolates in early 1990s, showed the presence of fever $>104 \mathrm{oF}$, toxemia, hepatomegaly, splenomegaly, abdominal tenderness and abdominal distension in significantly higher proportion of cases with Multi-Drug Resistant Salmonella Typhi (MDRST) as compared to typhoid fever due to sensitive strains. This could be due to the association of typhoid fever outbreaks with malnutrition, commonly seen in children under the age of five in developing countries. The presence of malnutrition enhances susceptibility to typhoid infection by alterations in the intestinal flora or other host defenses. ${ }^{8}$ In this study, nutritional status in patients are not obtained. Clinical presentation and laboratory features present between sensitive and resistant strain to first-line antibiotics (one or more) do not statistically show a significant difference.

Differences of susceptibility response to first-line antibiotics could be influenced by compliance of antibiotic consumption, self hygiene, cooked food and clean water consumption. Another important factor was genome from Salmonella Typhi itself. Different strains of Salmonella Typhi from 
all over the world and decreased outer membrane permeability that could lead to differences in clinical presentation and their susceptibility to antibiotic based on study in 5 cities of Indonesia (Medan, Jakarta, Pontianak, Makassar, and Jayapura)..$^{14,15,19}$

Limitation of this study is incompleted and the arrangement of data is unsystematic. Besides, unstandardized culture test procedure for typhoid fever in children also becomes a limitation in this study.

Based on data analysis, it can be concluded that there is no significant differences of clinical presentation in sensitive and resistant Salmonella Typhi isolates to the first-line antibiotics. Laboratory features in sensitive and resistant Salmonella Typhi isolates to first-line antibiotics also shows no significant differences.

Further research is needed to get more and better data and should be done prospectively so that clinical presentation and laboratory features could be shown more clearly and chosen antibiotic for children with typhoid fever could be more accurate. Procedure of susceptibility test to first-line antibiotics for typhoid fever in children should be decided by physician. Reported data should be arranged more clearly.

\section{References}

1. Dewan AM, Corner R, Hashizume M, Ongee ET. Typhoid fever and its association with environmental factors in the Dhaka Metropolitan Area of Bangladesh: a spatial and time-series approach. PLoS Negl Trop Dis. 2013;7(1):e1998.

2. Crump JA, Luby SP, Mintz ED. The global burden of typhoid fever. Bull World Health Organ. 2004;82(5):346-53.

3. Triono S. Riset Kesehatan Dasar. Laporan Nasional 2007. Jakarta: Badan Penelitian dan Pengembangan Kesehatan Departemen Kesehatan; 2008.

4. Chowta. Study of clinical profile and antibiotic response in typhoid fever. Indian J Med Microbiol. 2005;23(2):125-7.

5. Mathura, Chaudhary D, Simmkhada R, Pradhan M, Shresta P, Gurubacharya D. Study of clinical profile and antibiotic sensitivity pattern in culture positive typhoid fever cases. Kathmandu Univ Med J. 2005;3(4):376-9.

6. Kumar R, Gupta N, Shalini. Multidrugresistant typhoid fever. Indian J Pediatr. 2007;74(1):39-42.

7. Khandeparkar P. Reemergence of chloramphenicol in typhoid fever in the era of antibiotic resistance. J Assoc Physicians India. 2010;58(12):45-6.

8. Zaki SA, Karande S. Multidrug-resistant typhoid fever: a review. J Infect Dev Ctries. 2011;5(5):324-37.

9. Onyango D, Machoni F, Kakai R, Waindi EN. Multidrug resistance of Salmonella enterica serovars Typhi and Typhimurium isolated from clinical samples at two rural hospitals in Western Kenya. J Infect Dev Ctries. 2008;2(2):106-11.

10. Rahman, Ahmad, Begum. Multidrug resistant typhoid fever in children: a review. J Dhaka Med Coll. 2008;17(2):1216.

11. Mehul G, Hareshwaree H, Payal P, Abeda M. A study of clinical profile of multidrug resistant typhoid fever in children. Natl J Integr Res Med. 2011;2(3)87-90.

12. Alam A. Pola Resistensi Salmonella Enterica Serotipe Typhi, Departemen Ilmu Kesehatan Anak RSHS, Tahun 2006 - 2010. Sari Pediatr. 2011;12(5):296-301.

13. Choudhary A, Gopalakrishnan R, P. SN, Ramasubramanian, Ghafur A. Antimicrobial susceptibility of Salmonella enterica serovars ina tertiary care hospital in southern India. Indian J Med. 2013; 137(4)800-2.

14. Moehario LH, Tjoa E, Kalay VNKD, Abidin A. Antibiotic susceptibility patterns of Salmonella typhi in Jakarta and surrounding areas. In: Kumar MY, editor. Salmonella-A Divers. Superbug. 2012. p. 91-8.

15. Muthu G, Suresh A, Sumathy G. Studies on antimicrobial susceptibility pattern of Salmonella isolates from Chennai, India . Int J Pharma Bio Sci. 2011;2(2):435-42.

16. Saha SK, Darmstadt GL, Baqui $\mathrm{AH}$, Ruhulamin M, Santosham M, Nagatake T, et al. Rapid Identification and antibiotic susceptibility testing of Salmonella enterica Serovar Typhi isolated from blood implications for therapy. J Clin Microbiol. 2001;39(10):3583-5.

17. Khan MI, Soofi SB, Ochiai RL, Khan MJ, Muhammad S, Habib MA, et al. Epidemiology ,clinical presentation, and patterns of drug resistance of Salmonella Typhi in Karachi, Pakistan. J Infect Dev Ctries. 2012;6(10):704-14.

18. Dimitrov T, Udo EE, Albaksami O, Al-Shehab S, Kilani A, Shehab M, et al. Clinical and microbiological investigations of typhoid fever in an infectious disease hospital in Kuwait. J Med Microbiol. 2007;56(4):538- 
44.

19. Moehario LH. The molecular epidemiology of Salmonella Typhi across Indonesia reveals bacterial migration. J Infect Dev Ctries. 2009;3(8):579-84. 